\title{
A QUALIFICAÇÃO DA MULHER ADULTA: A DIMENSÃO FAMILIAR
}

\author{
Bravo Nico ${ }^{1}$ \\ Luísa Carvalho ${ }^{2}$ \\ Lurdes Nico ${ }^{3}$ \\ Joana Silva ${ }^{4}$
}

\section{Introdução}

As pessoas sempre aprenderam em diferentes lugares e tempos da sua vida. Já vão distantes os tempos em que se pensava que o "aprender" com consequência nas trajectórias académicas, profissionais e vitais dos indivíduos, se restringia ao espaço da sala de aula. Hoje, os ambientes de aprendizagem formais (escola tradicional), informais (trabalho, família, o aprender autónomo) e não formais (colectividades, associações, momentos conviviais e lúdicos) concorrem para a formação global do indivíduo e são, de forma crescente, considerados no percurso académico de cada indivíduo.

Como já referimos, na sociedade actual, a educação não se resume apenas ao espaço e tempo escolares. A expressão "life long learning" traduz aquilo que conhecemos como aprendizagem ao longo da vida. Neste contexto, a aquisição de saberes, conhecimentos e competências já não ocorrem "num único tempo e num único espaço como se aceitava no passado" (Leitão 2002: 75). Na realidade, a "deslocalização" da aprendizagem das escolas, para outros tempos e outros contextos, remete-nos para outras aprendizagens, nomeadamente as que ocorrem em contextos não formais e informais (Canário, 2002; Nogueira, 1996; Bernet, 1993). Costa (2002:10) refere, inclusive, a existência, na sociedade actual, de uma "multiaprendizagem". Para Landry (1991:21-22, citado por Cavaco, 2002) "a aprendizagem é um processo dialéctico que integra a experiência e a teoria, a observação e a aç̧ão."

Hoje, a realidade aponta-nos para uma multiplicidade de experiências de aprendizagem das pessoas ao longo da vida. Adquiridas várias competências é importante que exista uma rede de oferta de oportunidades de reconhecimento e certificação dessas competências.

\section{Roteiro Conceptual}

Na presente comunicação, apresentamos três percursos de educação e formação, de três mulheres, no âmbito dos processos de reconhecimento, validação e certificação de competências.

Importa, desde logo, definir alguns conceitos presentes ao longo da comunicação

\subsection{Educação de Adultos}

As competências básicas (ler, escrever e contar) são fundamentais, pois sem elas não poderá ocorrer aprendizagem ao longo da vida, numa perspectiva autónoma e em múltiplos contextos, de forma "sólida, estruturada e certificada" (Silva et al: 2002).

O desenvolvimento tecnológico e científico, a que assistimos diariamente, exige uma (re) definição das competências básicas. O "Memorando da Aprendizagem ao Longo da Vida"

\footnotetext{
${ }^{1}$ Departamento de Pedagogia e Educação da Universidade de Évora

${ }^{2}$ Escola Superior de Educação do Instituto Politécnico de Portalegre

${ }^{3}$ Direcção Regional de Educação do Alentejo

${ }^{4}$ Escola Comunitária de São Miguel de Machede
} 
5 apela à necessidade de se assegurarem "as novas competências básicas para todos", as quais são, para Silva et al (2002), entre outras, as "Tecnologias da Informação e Comunicação, a Internet, a utilização corrente do computador, o espírito empreendedor e científico, ...". A mesma autora refere que aos cidadãos de hoje não basta a educação e formação iniciais. É necessário continuar a aprender ao longo da vida, reforçando $a$ "capacidade de aprender mais $e$ também de desaprender".

No Relatório Nacional dos Cursos de Educação e Formação de Adultos (2000/2001), uma das conclusões apresentadas é a de que "os adultos, ao adquirirem um conjunto de competências-chave, se mobilizam para realizar percursos subsequentes de educação e formação (...) a aquisição de competências básicas é um "passaporte" para a Aprendizagem ao Longo da Vida." (Leitão: 2002).

Há autores que distinguem formação de educação de adultos. Canário (1999) utiliza ambas as expressões e clarifica o sentido atribuído a cada uma delas, associando a formação de adultos à formação profissional.

Melo (1978: 99) considera a Educação como "um processo libertador que tem em vista a autonomia das populações e não a sua dependência”. Para Patrício (2004) a educação "ocorre necessariamente numa circunstância, numa situação concreta. (...) Toda a educação toda a aprendizagem, é situada". Neste contexto, a Educação de Adultos é entendida "como uma organização colectiva autogerida, criada para fazer face aos múltiplos problemas quotidianos" (Melo, A. \& Benavente, A., 1978: 11), "um conjunto de teorias, estratégias e modelos organizativos" (Osorio, 2003: 217).

No que diz respeito às teorias de Educação de Adultos, não é possível identificar, um modelo considerado como único e mais adequado, dada a complexidade do conceito e dos sujeitos envolvidos. Para Osorio (2003: 119) " a pessoa adulta não é apenas um sujeito de formação, é também um sujeito e um agente de desenvolvimento pessoal e social”. (...). A Educação de Adultos é, assim, entendida como um "conjunto de teorias, estratégias e modelos organizativos.".

A UNESCO, e outros organismos internacionais têm contribuído para a realização de vários momentos de reflexão/debate sobre a temática da Educação de Adultos, compreendida, sempre, num contexto histórico e político que lhe está subjacente.

No âmbito das primeiras conferências internacionais, destaca-se a Conferência de Elsinor (Dinamarca, 1949). O período após a segunda guerra mundial é considerado como um momento de avanço significativo nas medidas e políticas ao nível da Educação de Adultos. Acentuam-se os valores da "educação democrática, o equilíbrio entre os direitos do indivíduos e os da comunidade" (Osorio: 2003). Mais tarde, em 1960, na Conferência de Montreal (Canadá), começou a valorizar-se o conceito de Educação Permanente e a relação desta com a Educação de Adultos. Assim sendo, refere-se que, "no contexto da Educação Permanente se reconhece a Educação de Adultos como um elemento específico e indispensável da educação." (Osorio, 2003). No decorrer das reflexões proporcionadas por esses encontros, emerge cada vez mais a importância do "direito a aprender ao longo da vida", o qual deve, de acordo com Marín, (citado por Osorio, 2003: 222), quando este se refere "aos conhecimentos e aos comportamentos que não são fáceis de adquirir no meio social, de um modo assistemático (...)".

$\mathrm{Na}$ Conferência de Hamburgo (Alemanha, 1997), definiu-se que "a educação de adultos compreende a educação formal e a permanente, a educação não formal e toda a gama de oportunidades da educação informal e ocasional existentes numa sociedade educativa multicultural.".

Hoje, é evidente a necessidade de ultrapassar a concepção inicial de Educação de Adultos centrada no aspecto da Alfabetização, situando-a para lá dos processos de aprendizagem formais (escolarização), que António Nóvoa (citado por Cavaco:2002) critica como sendo os "métodos para dar aos adultos a escola que não tiveram na infância ."

\footnotetext{
${ }^{5}$ COMISSÃO EUROPEIA (2000). Memorando sobre Aprendizagem ao Longo da Vida. Bruxelas.
} 


\subsection{Contextos de Aprendizagem}

Procurando valorizar-se as diferentes formas e contextos em que ocorre a aprendizagem, é pertinente distinguir:

a aprendizagem formal é a que decorre em instituições de ensino e formação e conduz a diplomas e qualificações reconhecidos e onde se verifica uma "estruturação prévia de programas e horários, na existência de processos avaliativos e de certificação" (Canário, 1999, citado por Cavaco, 2002, p 29.);

(ii) a aprendizagem não-formal " $n$ ão conduz a certificados formais e pode ocorrer no local de trabalho (...) organizações ou serviços (...) (aulas de arte, música e desporto ou ensino privado...)"; (Leitão et al, 2001: 8) e constitui "a única forma de aprendizagem da maioria dos adultos" (Correia \& Cabete. 2002: 45);

(iii) a aprendizagem informal é uma aprendizagem não organizada, intencional ou não, ocorrendo em "situações potencialmente educativas, mesmo que não conscientes, nem intencionais (...) correspondendo a situações pouco estruturadas e organizadas" " (Canário: 1999, citado por Cavaco, 2002: 29).

Coombs (citado por Cavaco, 2002:29) define Educação Informal como "um processo que ocorre ao longo da vida, através do qual cada pessoa adquire e acumula conhecimentos, capacidades, atitudes; a partir das experiências quotidianas e da interacção com o meio ambiente - em casa, no trabalho, (...) a partir do exemplo dado pela familia e amigos, ...”.

As aprendizagens realizadas nos contextos informais podem ser de dois tipos (Pain: 1990, citado por Cavaco, 2002: 39):

(i) as que os indivíduos realizam nos meios em que se movem (família, amigos,...);

(ii) as que se concretizam na sociedade, em geral.

A esses contextos informais surge associada a formação que se adquire pela experiência do quotidiano (Idem: ibidem).

Para Lengrand (citado por Cavaco, 2002: 40), o contexto familiar é muito importante pelo contributo que tem "na aquisição de competências de expressão, de comunicação, de relação interpessoal".

Nas sociedades actuais, os saberes, os conhecimentos e as competências necessárias para elevar os níveis de qualificação são cada vez mais exigentes. Investir nessa área, é um factor fundamental e que pode marcar a diferença entre os diferentes países, regiões e locais, naquilo a que Trigo (2002: 24) define como sendo o que "distingue, hoje, as sociedades mais avançadas das demais".

A Teoria do Capital Humano, apresentada por Theodore Schultz (1961) e Gary Becker (1962), demonstra claramente a relação existente entre os sistemas de educação e formação das pessoas, numa perspectiva de aprendizagem ao longo da vida, e o desenvolvimento económico e social da sociedade em que estão inseridos. Os estudos de Michael Porter também dão enorme importância à educação e formação das pessoas nos vários elementos que integram o "Modelo de Diamante de Porter" (Trigo, 2002).

\subsection{Competência}

Se é unânime afirmar que vários autores defendem a existência de diferentes contextos de aprendizagem, já aqui referidos, nos quais os indivíduos adquirem saberes e conhecimentos 
nas diferentes áreas, o mesmo não parece ocorrer quando se procura definir e compreender o conceito de competência.

Se para Correia \& Cabete (2002: 48), competência é entendida como um conceito com múltiplos significados, "conceito polissémico, abrangendo conhecimentos, capacidades, dimensões metacognitivas e simbólicas que se mobilizam permanentemente na acção", já Perrenoud (2000) define-a como " a faculdade de mobilizar um conjunto de recursos cognitivos (saberes, capacidades, informações, etc) para solucionar com pertinência e eficácia uma série de situações."

No processo de Reconhecimento, Validação e Certificação de Competências (RVCC), privilegia-se o conceito de competência-chave, ou competência de vida, que "assenta na mobilização de conhecimentos, saberes e técnicas para a resolução de uma situação concreta do quotidiano pessoal, social e profissional do adulto" (Alonso et al, 2001). Neste contexto, as competências "são entendidas numa perspectiva sistémica, como a mobilização em acto de saberes, capacidades e recursos, externos e pessoais, de natureza cognitiva, emocional e afectiva, construidos e integrados em situações de aprendizagem explícita ou implícita, em contextos diversificados de experiência pessoal, profissional, social, ou seja de vida." (DGFV, 2004).

Se, por um lado, é importante a aquisição permanente de competências básicas novas para que os indivíduos consigam integrar-se e acompanhar o desenvolvimento tecnológico e científico, por outro lado, importa criar mecanismos que proporcionem oportunidades de formação adaptadas aos perfis e percursos de cada um, bem como um sistema de reconhecimento, validação e certificação das competências adquiridas (RVCC).

\subsection{A mulher no campo da qualificação e organização familiar}

Desde sempre os sujeitos foram diferenciados (sexo masculino/sexo feminino) não só em virtude da circunstância biológica, mas também com base na divisão do trabalho, do poder e influência social.

As diferenças entre homens e mulheres, desde sempre, interessam e cativaram a atenção. De facto, desde a Antiguidade, filósofos gregos (Platão e Aristóteles) até aos tempos modernos com pensadores e pedagogos como Christine de Pisan, a Marquesa de Mainternon, Fénelon, Alexandre de Gusmão e Rousseau, entre outros, dirigiram a sua atenção para esta problemática (Vieira: 2003).

A segregação sexual na divisão de tarefas, a distinção clara de papéis, o modelo de família tradicional já se podia verificar (segundo Badinter) nos tempos dos fósseis de hominídeos; nas sociedades agrárias, patriarcais (cerca de seis mil anos atrás), ou na Revolução Industrial, na segunda metade do séc. XIX (Vieira, 2003: 21-22). "Todavia, esta distribuição do trabalho, que exaltava o papel público do homem e confinava à mulher à esfera do lar, foi sendo, progressivamente, posta em causa, ao longo dos últimos dois séculos, tendo tido especial destaque na segunda metade do século XX." (Vieira, 2003:23).

Contudo, não houve a preocupação ao longo dos anos de se verificar a verosimilhança dessas tradicionais e enviesadas concepções científicas (muitas vezes representativas das visões masculinas da ciência) ou ter em conta a investigação científica acerca das características do homem e da mulher que foram, assim passando de geração em geração (Vieira:2003; Pereira: 2005).

O papel das mulheres face ao trabalho, política e educação alterou-se com a mudança de regime ocorrida em 1974, já que se verificou que havia "um certo subaproveitamento das competências pessoais de mais de metade da população (...) As mulheres estavam entre os mais pobres; relativamente às habilitações académicas, eram quem detinha as maiores taxas de analfabetismo; no que diz respeito ao trabalho, a taxa de participação feminina no mundo laboral era reduzida e a condição específica de doméstica era representativa de uma vasta maioria das mulheres." (Pereira, 2005:99)

Após o 25 de Abril de 1974, e com o intuito a nível externo de combater o "fosso" que nos separava dos países da zona Euro - internamente, a existência do problemas do elevado 
nível de analfabetismo, frágil qualificação profissional, pobreza -, de acordo com Barbosa (2004, citado por Pereira, 2005:206), identificam-se duas tendências:

(i) a tendência sistémico - institucional, com um carácter formativo mais formal

(ii) a tendência humanista - comunitária, baseada na lógica de Paulo Freire da conscientização. Segundo esta última, "as acções educativas partem da livre iniciativa de agentes locais, vagamente apoiadas pelas autarquias, instituições religiosas associações, que persistem com dificuldade, na base de uma rede complexa de parcerias e partenariados. Este tipo de aprendizagem, que não é processada nem reconhecida oficialmente, ou seja, não é equiparada, no seu valor, às aprendizagens escolares.".

Canço (2002, citado por Pereira, 2005:105), numa apreciação geral, a situação actual das mulheres portuguesas face aos homens, é considerada desnivelada e sintoma paradigmático das diferenças sociais provocadas pela tradicional interpretação dicotómica do que é específico dos homens e o que é específico das mulheres. A incidência dos baixos rendimentos sobre as mulheres, torna-as particularmente vulneráveis à pobreza e à exclusão social. "Para tal contribui a especificidade da sua participação na vida familiar, económica e social: auferem, em média, salários mais baixos, são mais afectadas pelo desemprego, têm menor protecção social devido ao tempo de participação na actividade económica: por outro lado, com mais esperança de vida, comparativamente com os homens, as idosas encontram-se muitas vezes em situações precárias...”.

De acordo com Arroteia (2002), no que respeita às mulheres, registou-se, entre $1991 \mathrm{e}$ 2001, um aumento da ocupação das mesmas: 25\%. Em igual período, evidenciou-se, também, um "acréscimo da feminização do emprego", também registado ao nível do ensino superior $(19,7 \%)$, como consequência da emancipação da mulher e do seu papel cada vez mais interventivo e participativo na sociedade portuguesa.

\section{Centros de Reconhecimento, Validação e Certificação de Competências}

No que à Educação e Formação de Adultos diz respeito, há neste momento duas importantes vertentes de actuação: Cursos de Educação e Formação de Adultos (cursos EFA de dupla certificação) de cariz marcadamente formativo e Centros Novas Oportunidades que visam o Reconhecimento, a Validação e a Certificação de Competências (RVCC).

\subsection{Enquadramento histórico/ legal}

O sistema RVCC inscreve-se na Estratégia Europeia para o Emprego e no Plano Nacional de Emprego (PNE) e, actualmente, insere-se na iniciativa governamental Novas Oportunidades. Este dispositivo é uma realidade hoje presente em todo o território nacional, envolvendo um número significativo de adultos que, através desta janela formal, têm vindo a alterar, de forma significativa, os seus índices de escolarização e também a possibilidade de continuar um processo de educação e formação ao longo da vida.

Esta possibilidade formal de reconhecimento, validação e certificação de competências adquiridas pelos indivíduos em contextos não escolares de aprendizagem teve a sua génese no Decreto-Lei n. ${ }^{\circ}$ 74/91, de 9 de Fevereiro, que regulamenta a Lei de Bases do Sistema Educativo (Lei n. ${ }^{\circ}$ 46/86, de 14 de Outubro).

No seguimento desta determinação, é criada, em 28 de Setembro de 1999 (cf. DecretoLei n. ${ }^{\circ}$ 387/99), a ANEFA (Agência Nacional de Educação e Formação de Adultos) sendo-lhe atribuída a missão de construir "um sistema de reconhecimento e validação das aprendizagens informais dos adultos, visando a certificação escolar e profissional".

Através da Portaria n. ${ }^{\circ}$ 1082-A/2001, de 5 de Setembro, são criados os Centros RVCC (Centros de Reconhecimento, Validação e Certificação de Competências), numa rede de âmbito nacional que se tem vindo a expandir até à actualidade, para que possa "(...) ser dada a oportunidade a todos os cidadãos, e em particular aos adultos menos escolarizados e aos activos empregados e desempregados, de verem reconhecidos os conhecimentos e as competências que foram adquirindo por via não formal e informal, em diferentes contextos de 
vida e de trabalho, apoiando-os no (re) desenhar dos seus percursos de desenvolvimento pessoal e profissional,...” (DGFV, 2006)

A Portaria atrás referida foi alterada pela Portaria n. ${ }^{\circ} 86 / 2007$, de 12 de Janeiro, a qual actualizou o sistema RVCC, decorrente da experiência evidenciada desde 2001, com a implementação deste dispositivo de educação e formação de adultos.

Através do Decreto-Lei n. ${ }^{\circ}$ 208/2002, foi extinta a ANEFA, dando lugar à Direcção Geral de Formação Vocacional, na sequência da publicação da nova Lei Orgânica do Ministério da Educação, a qual foi, recentemente, extinta e substituída pela Agência Nacional para a Qualificação, I.P., abreviadamente designada por ANQ, e que tem como missão "coordenar a execução das políticas de educação e formação profissional de jovens e adultos e assegurar o desenvolvimento e a gestão do sistema de reconhecimento, validação e certificação de competências" (Art. 17. ${ }^{\circ}$, Decreto-Lei n. ${ }^{\circ}$ 213/2006, de 27 de Outubro).

Actualmente, os Centros RVCC destinam-se a adultos com idade igual ou superior a 18 anos de idade, que não possuam o $4 .^{\circ}$, o $6 .^{\circ}, 9^{\circ}$ e $12 .^{\circ}$ anos de escolaridade e que, por isso, pretendam obter uma certificação escolar equivalente ao $1 .^{\circ}, 2 .^{\circ}$ e $3 .^{\circ}$ Ciclos do Ensino Básico ou ao Nível Secundário (desde Janeiro de 2007).

A rede nacional de RVCC é co-financiada pelo Programa de Desenvolvimento Educativo para Portugal, conhecido por PRODEP III (Portaria n. ${ }^{\circ} 1082-\mathrm{A} / 2001$, artigo $4 .^{\circ}$, de 5 de Setembro).

No âmbito do programa do Governo denominado Novas Oportunidades, foram criados, até ao momento, 268 Centros em todo o país.

\subsection{Os níveis de qualificação em Portugal e Alentejo}

No que à Educação e Formação de Adultos diz respeito, importa referir que, em Portugal, há cerca de 3.500.000 de activos com um nível de escolaridade inferior ao ensino secundário, dos quais $\mathbf{2 . 6 0 0 . 0 0 0}$ apresentando um nível de escolaridade inferior ao $9 .^{\circ}$ ano, não esquecendo a percentagem de 9\%de analfabetos literais identificados em 2001 (INE, 2002).

No Alentejo, de acordo com o Recenseamento de 2001, 68\% da população não tem a escolaridade básica obrigatória ( $9 .^{\circ}$ ano), conforme apresentado no quadro seguinte:

Quadro 1 - Níveis de Escolaridade no Alentejo

\begin{tabular}{|c|c|c|c|}
\hline \multirow{2}{*}{$\begin{array}{l}\text { Nível de Ensino } \\
\text { Atingido }\end{array}$} & \multirow{2}{*}{$\begin{array}{l}\text { Frequências } \\
\text { absolutas }\end{array}$} & \multicolumn{2}{|c|}{ Frequências relativas (\%) } \\
\hline & & Alentejo & Portugal \\
\hline Nenhum & 111580 & 20,9 & 14,2 \\
\hline $1^{0}$ ciclo & 192576 & 36,0 & 35,2 \\
\hline $2^{\circ}$ ciclo & 59642 & $\begin{array}{l}11,1 \\
(68,0)\end{array}$ & $\begin{array}{l}12,6 \\
(62,0)\end{array}$ \\
\hline$\overline{3^{\circ} \text { ciclo }}$ & 54412 & 10,1 & 10,8 \\
\hline Secundário & 73660 & 13,7 & 15,7 \\
\hline Médio & 2552 & 0,5 & 0,8 \\
\hline Superior & 41324 & 7,7 & 10,7 \\
\hline Totais & 535753 & 100,0 & 100,0 \\
\hline
\end{tabular}

Fonte: INE, Censos de 2001.

No período 2001-2005, foram certificados na Região Alentejo, nos seis centros existentes até então, aproximadamente três mil e cem adultos. 
Até ao ano de 2005, operaram, no Alentejo, seis Centros de Reconhecimento, Validação e Certificação de Competências:

- Ferreira do Alentejo (Esdime - Agência para o Desenvolvimento Local no Alentejo Sudoeste);

- Évora (Fundação Alentejo);

- Portalegre (Centro de Formação Profissional do Instituto de Emprego e Formação Profissional);

- Santiago do Cacém (Associação de Desenvolvimento do Litoral Alentejano);

- Serpa (Rota do Guadiana - Associação de Desenvolvimento Integrado);

- Alcáçovas (Terras de Dentro - Associação para o Desenvolvimento das MicroRegiões Rurais)

A rede de Centros Novas Oportunidades do Alentejo é, actualmente, constituída por 32 Centros de diferentes tipologias (cf. Quadro 2). O alargamento da rede de $\mathrm{CNO}$ às escolas públicas do Alentejo ocorreu no ano de 2006, em fases distintas. Em Novembro desse ano, ocorreu também o alargamento do Sistema RVCC ao Nível Secundário (12. ${ }^{\circ}$ ano).

Quadro 2 - Rede de Centros Novas Oportunidades

\begin{tabular}{|l|c|}
\hline \multicolumn{1}{|c|}{ Centros Novas Oportunidades do Alentejo } & $\mathbf{N}^{\mathbf{0}}$ \\
\hline Entidades Privadas & 7 \\
\hline Entidades Públicas & 20 \\
\hline IEFP & 5 \\
\hline \multicolumn{2}{|c|}{ Total } \\
\hline
\end{tabular}

Fonte: DRE Alentejo, 2006.

\section{O Estudo Empírico}

Os dados que se apresentam referem-se a resultados obtidos no âmbito de um Projecto de Investigação do Centro de Investigação em Educação e Psicologia (CIEP), da Universidade de Évora e decorrem da investigação realizada no âmbito do projecto de investigação Cartografia Educacional das Freguesias de São Miguel, Nossa Senhora de Machede e Torre de Coelheiros, promovido pelo Departamento de Pedagogia e Educação da Universidade de Évora e financiado pela Fundação Calouste Gulbenkian.

$\mathrm{Na}$ comunicação aqui apresentada, procuramos apresentar e avaliar o percurso de mulheres que frequentaram o processo, durante e após o processo RVCC, através da análise de entrevistas efectuadas a três adultos residentes na pequena freguesia de São Miguel de Machede (concelho de Évora).

Nas entrevistas realizadas, procuramos apresentar o caso de três mulheres que protagonizaram um percurso de aprendizagem e de qualificação, através de processos de Reconhecimento, Validação e Certificação de Competências (RVCC).

\subsection{Breve caracterização dos sujeitos da amostra}

Os sujeitos entrevistados são residentes na freguesia de São Miguel de Machede (concelho de Évora), do sexo feminino, com idades compreendidas entre os 31 e os 46 anos de idade e realizaram os respectivos processos de RVCC através da Fundação Alentejo (Évora), que efectuou o processo em regime de itinerância na Escola Comunitária de São Miguel de Machede.

\section{Análise global da informação recolhida}




\subsection{Percurso Pessoal/Profissional}

A partir da análise de conteúdo das entrevistas, identificámos alguns dos momentos mais significativos do percurso pessoal e profissional dos indivíduos.

No Quadro 3, conhecemos as profissões desempenhadas assim como as razões do abandono precoce dos estudos.

\begin{tabular}{|c|c|c|c|}
\hline Sub-Categoria & Conteúdo dos Indicadores & $\begin{array}{l}\text { Unid. } \\
\text { Reg. }\end{array}$ & Unid. Enum. \\
\hline $\begin{array}{l}\text { A1-PERCURSO } \\
\text { PESSOAL/PROFISSIONAL }\end{array}$ & $\begin{array}{l}\text { Abandono dos estudos } \\
\text { Serviço Doméstico } \\
\text { Trabalho fabril } \\
\text { Contexto familiar (dificuldades económicas) } \\
\text { Serviços Gerais } \\
\text { Trabalho rural } \\
\text { Cuidar crianças } \\
\text { Desemprego }\end{array}$ & $\begin{array}{l}6 \\
6 \\
3 \\
2 \\
1 \\
1 \\
1 \\
1\end{array}$ & $\begin{array}{l}3 \\
2 \\
1 \\
2 \\
1 \\
1 \\
1 \\
1\end{array}$ \\
\hline A1 Total & & 21 & 3 \\
\hline
\end{tabular}

No que respeita ao percurso profissional, dois dos sujeitos evidenciam mais o serviço doméstico realizado em casas particulares, desde muito cedo, logo após a conclusão do $2 .{ }^{\circ}$ Ciclo do Ensino Básico (6. ${ }^{\circ}$ ano). Verifica-se que duas das respondentes abandonaram os estudos (6UR/3UE), devido a razões económicas. Para o terceiro indivíduo, a razão apontada para o abandono dos estudos foi o facto de " já não tinha motivos para andar a estudar" (1.1.7.) e "Eu andei na escola até aos 18 anos." (1.1.3.)

O trabalho fabril constituiu outra das actividades evidenciadas de forma significativa para apenas um dos sujeitos (3 UR) "(...) fui para uma fábrica - a APIS - (...) perto dos 15 anos" (3.1.6.); “(...)havia outra fábrica de parquet mas em corticite (...)e calhou-me a mim.” (3.1.8.)

\section{2. $\quad \underline{\text { Razões/motivações das aprendizagens }}$}

Quadro 4 - Razões/Motivações das aprendizagens

\begin{tabular}{|c|c|c|c|}
\hline Sub-Categoria & Conteúdo dos Indicadores & $\begin{array}{l}\text { Unid. } \\
\text { Reg. }\end{array}$ & Unid. Enum. \\
\hline $\begin{array}{l}\text { B1- RAZÕES/MOTIVAÇÕES } \\
\text { APRENDIZAGENS }\end{array}$ & $\begin{array}{l}\text { Prazer } \\
\text { Desafio } \\
\text { Novidade } \\
\text { Conhecimento } \\
\text { Necessidade } \\
\text { Querer fazer algo } \\
\text { Ambição profissional (novo emprego) } \\
\text { Descoberta } \\
\text { Acaso }\end{array}$ & $\begin{array}{l}4 \\
4 \\
3 \\
3 \\
2 \\
2 \\
1 \\
1 \\
1\end{array}$ & $\begin{array}{l}3 \\
2 \\
2 \\
2 \\
2 \\
2 \\
1 \\
1 \\
1 \\
1\end{array}$ \\
\hline B1 Total & & 21 & 3 \\
\hline
\end{tabular}

Ao analisarmos as razões/motivações que levam os indivíduos a efectuar aprendizagens, verificou-se que todos os indivíduos referiram o prazer (4UR) e o desafio (4 UR), seguido da novidade e o conhecimento como se pode depreender das seguintes citações:

- "Sinto-me bem saber mais qualquer coisa" (2.3.2.);

- "Eu qualquer coisa que faço é um desafio." (1.1.10.);

- "Se houver a oportunidade de aprendermos mais coisas, coisas diferentes é bom." (3.3.9.).

\subsection{Habilitações/Formação}


Quadro 5 - Habilitações/Formação

\begin{tabular}{|l|l|c|c|}
\hline \multicolumn{1}{|c|}{ Sub-Categoria } & \multicolumn{1}{|c|}{ Conteúdo dos Indicadores } & $\begin{array}{c}\text { Unid. } \\
\text { Reg. }\end{array}$ & Unid. Enum. \\
\hline B2- HABILITAÇÕES/FORMAÇÃO & Habilitações de acesso ao processo & 3 & 2 \\
& Acções de formação em contexto de trabalho & 1 & 3 \\
& Diplomas & 1 & 1 \\
& Projectos de nível local & 1 & 1 \\
\hline B2 Total & Acções de formação fora do contexto de trabalho & $\mathbf{8}$ & 1 \\
\hline
\end{tabular}

No que se refere às habilitações de acesso dos indivíduos ao processo de Reconhecimento, Validação e Certificação de Competências, todos os sujeitos tinham o 6. ${ }^{\circ}$ ano de escolaridade (2. ${ }^{\circ}$ Ciclo do Ensino Básico), tendo um apresentado a frequência do $9 .^{\circ}$ ano de escolaridade.

Apenas um dos indivíduos se refere à obtenção de um outro diploma "Tenho o diploma de marceneiro." (1.1.9.) e à realização de projectos de nível local na Associação Suão ${ }^{6}$, nos quais efectuou aprendizagens importantes "Já trabalhei com o gabinete da papelada." (1.1.12.), que constitui uma espécie de Loja do Cidadão Micaelense (a funcionar desde 1998).

Outras acções de formação dentro e fora do contexto de trabalho foram referidas por apenas um dos indivíduos. A primeira relacionada com o trabalho fabril "Na Salsicharia (...) tive várias formações (atendimento ao público, Higiene e Segurança no Trabalho)." (3.2.5.) e a segunda com um Curso de Informática de curta duração, realizado noutra instituição local.

\subsection{Momentos de Aprendizagem}

\begin{tabular}{|l|l|c|c|}
\hline \multicolumn{1}{|c|}{ Sub-Categoria } & \multicolumn{1}{|c|}{ Conteúdo dos Indicadores } & $\begin{array}{c}\text { Unid. } \\
\text { Reg. }\end{array}$ & Unid. Enum. \\
\hline B3-MOMENTOS DE APRENDIZAGEM & Leitura & 4 & 2 \\
& Teatro & 1 & 2 \\
& Grupo Coral & 1 & 1 \\
& Experiência de vida & 1 & 1 \\
\hline B3 Total & Música & $\mathbf{9}$ & 1 \\
\hline
\end{tabular}

Como se pode verificar no Quadro 6, o momento de aprendizagem mais significativo para todos os sujeitos é a leitura (4UR), seguido do teatro (2UR/2UE) "Eu adoro ler mesmo com quase 50 anos." (1.3.10.), "Não tenho tempo mas adoro ler." (3.5.12.), "Eu ia aprendendo pela vida(...)."

Todos os outros momentos foram referenciados apenas por um indivíduo (Grupo Coral, Experiência de Vida, Música).

\subsection{Ambientes de Aprendizagem}

Relativamente aos ambientes em que as aprendizagens ocorreram, podemos distinguir três ambientes: o formal (aprendizagens adquiridas nos sistemas institucionais de educação e formação); o não-formal (aprendizagens que são produto de outras actividades de formação não institucionais, como algumas de carácter profissional) e o informal (aprendizagens decorrentes das actividades da vida quotidiana, relacionadas com o trabalho, a família, o lazer).

Quadro 7 - Ambientes de Aprendizagem

Sub-Categoria Conteúdo dos Indicadores Unid.
Reg. Unid. Enum.

\footnotetext{
${ }^{6}$ Suão - Associação para o Desenvolvimento Comunitário, localizada em São Miguel de Machede, onde se localiza a Escola Comunitária já referida anteriormente.
} 


\begin{tabular}{|l|l|c|}
\hline B4.1. - Não-Formais & Cursos de Formação & 3 \\
& Escola Comunitária (Suão) & 4 \\
& Quotidiano/Vida & 3 \\
& Relacionamento interpessoal & 2 \\
& & 1 \\
\hline B4.1. -Total & Local de trabalho & $\mathbf{1 2}$ \\
\hline B4.2. -Informais & Família (casa) & 8 \\
& Internet & 4 \\
\hline B4.2. -Total & & 3 \\
\hline B4 Total & & 1 \\
\hline
\end{tabular}

Analisando o Quadro 7, constatamos que a realização das aprendizagens ocorre, com maior frequência no ambiente informal (13UR) e também no ambiente não formal (12UR), pois de acordo com os dados obtidos, a diferença entre ambos é relativa: "Tive a fazer um Curso na Singer." (2.1.12), "Com a minha irmã (...) o que uma sabe ajuda a outra." (3.3.20.). No ambiente não formal, destacam-se as aprendizagens efectuadas na Escola Comunitária da freguesia (4UR/2UE). No ambiente informal, surge o local de trabalho (8UR/3UE) e a família (4UR/3UE).

\subsection{Estratégias de Aprendizagem}

\begin{tabular}{|c|c|c|c|}
\hline \multicolumn{4}{|c|}{ Quadro 8 - Estratégias de Aprendizagem } \\
\hline Sub-Categoria & Conteúdo dos Indicadores & $\begin{array}{l}\text { Unid. } \\
\text { Reg. }\end{array}$ & Unid. Enum. \\
\hline $\begin{array}{l}\text { B6- } \quad \text { ESTRATÉGIAS } \\
\text { APRENDIZAGENS }\end{array}$ & $\begin{array}{l}\text { Apontamentos } \\
\text { Rascunhos } \\
\text { Observação/Atenção } \\
\text { Isolamento (tentativa por si) } \\
\text { Experiência do quotidiano } \\
\text { Persistência } \\
\end{array}$ & $\begin{array}{l}3 \\
2 \\
2 \\
2 \\
1 \\
1\end{array}$ & $\begin{array}{l}1 \\
2 \\
2 \\
2 \\
1 \\
1\end{array}$ \\
\hline B6 Total & & 11 & 3 \\
\hline
\end{tabular}

Procurando conhecer o modo como os indivíduos realizam as suas aprendizagens, foram identificadas seis estratégias diferenciadas, sendo que mais referenciada são os apontamentos por um indivíduo (3UR) "Eu preciso tirar muitos apontamentos..." (1.2.12). Também foram referidos os rascunhos, "Normalmente escrevo em papelinhos." (3.4.16.) e a observação/atenção "Foi só ver e ouvir!" (1.3.7./referindo-se à medição da tensão arterial na Associação Suão). O isolamento “(...) sempre me desenraquei sozinha." (1.3.4.) é outra das estratégias identificadas pelos indivíduos (2UR/2UE). Particularmente interessante, esta última estratégia, por constituir um momento para o indivíduo, tentar sozinho, algo que lhe foi ensinado ou observado e, dessa forma, conseguir efectuar as aprendizagens e consequentemente, a aquisição de competências.

\subsection{Processo de Reconhecimento, Validação e Certificação de Competências (Rvcc)}

Quadro 9 - Conhecimento da existência dos Centros RVCC

\begin{tabular}{|l|l|c|c|}
\hline \multicolumn{1}{|c|}{ Sub-Categoria } & \multicolumn{1}{|c|}{ Conteúdo dos Indicadores } & $\begin{array}{c}\text { Unid. } \\
\text { Reg. }\end{array}$ & Unid. Enum. \\
\hline C1 CONHECIMENTO DA & Escola Comunitária Suão & 3 & 1 \\
EXISTÊNCIA DOS CENTROS RVCC & Amigos & 1 & 1 \\
& Família & 1 & 1 \\
\hline C1 Total & Folhetos & $\mathbf{6}$ & 1 \\
\hline
\end{tabular}

Podemos concluir, após a análise do Quadro 9, que os indivíduos tomaram conhecimento da existência dos processos de RVCC através de ambientes não formais, nomeadamente a Escola Comunitária de São Miguel de Machede (3UR/2UE). Todos os outros elementos foram referenciados apenas por um indivíduo. Mais uma vez, notamos a importância dos contextos informais de aprendizagem como os amigos e a família. 
Quadro 10 - Caracterização do Processo RVCC

\begin{tabular}{|c|c|c|c|}
\hline Sub-Categoria & Conteúdo dos Indicadores & $\begin{array}{l}\text { Unid. } \\
\text { Reg. }\end{array}$ & Unid. Enum. \\
\hline $\begin{array}{lll}\text { C2- } & \text { CARACTERIZAÇÃO } & \text { DO } \\
\text { PROCESSO DE RVCC } & \end{array}$ & $\begin{array}{l}\text { Dossier Pessoal } \\
\text { Reconhecimento e Validação (Competências } \\
\text { adquiridas longo da vida) } \\
\text { Experiência de Vida } \\
\text { Áreas de Competência-Chave } \\
\text { Inscrição } \\
\text { Conclusão } \\
\text { História de Vida } \\
\text { Duração }\end{array}$ & $\begin{array}{l}6 \\
5 \\
4 \\
3 \\
3 \\
2 \\
2 \\
2 \\
1\end{array}$ & $\begin{array}{l}3 \\
2 \\
2 \\
2 \\
2 \\
2 \\
2 \\
2 \\
1\end{array}$ \\
\hline C2 Total & & 25 & 3 \\
\hline
\end{tabular}

No que diz respeito à caracterização do processo, os indivíduos referenciam vários aspectos inerentes ao processo de reconhecimento, validação e certificação de competências. Evidencia-se a importância atribuída pelos indivíduos ao Dossier Pessoal (6UR/3UE). É no Dossier Pessoal que cada adulto operacionaliza as competências adquiridas ao longo da vida à luz de um Referencial de Competências-Chave de Nível Básico já mencionado. É aí que o adulto organiza e sistematiza a informação produzida e recolhida durante o processo de RVCC, ao nível da sua história de vida pessoal, social e profissional e dos projectos futuros "(...)tínhamos de fazer um dossier que preenchíamos com capitulos ao longo da nossa vida.” (1.5.10.).

A própria metodologia de RVC assume relevância para dois dos indivíduos (5UR), sendo evidente também a importância da experiência de vida (4UR/2UE) "Ali é demonstrar experiência.” (1.7.8.); “(...) apresentei o que sabia fazer através do dossier.” (2.4.5.). Outros aspectos referidos como a inscrição, a conclusão do processo e a história de vida (entendida no processo como metodologia no âmbito das abordagens (auto) biográficas). A duração do processo foi referida apenas por um indivíduo. Este prosseguiu estudos ao nível do Ensino Secundário (Recorrente, por Módulos Capitalizáveis), o que poderá ser entendido pela natureza dos objectivos de vida (académicos) diferenciados relativamente aos outros dois indivíduos.

Quadro 11 - Motivação/Expectativas iniciais

\begin{tabular}{|l|l|c|c|}
\hline \multicolumn{1}{|c|}{ Sub-Categoria } & \multicolumn{1}{|c|}{ Conteúdo dos Indicadores } & $\begin{array}{c}\text { Unid. } \\
\text { Reg. }\end{array}$ & Unid. Enum. \\
\hline C3- MOTIVAÇÃO/ & Obtenção do diploma & 3 & 2 \\
& Desconhecimento & 2 & 1 \\
& Duração do Processo & 1 & 1 \\
& Novidade & 1 & 1 \\
& Ambição por novo emprego & 1 & 1 \\
& Nova Oportunidade & 1 & 1 \\
\hline C3 Total & Ocupação do tempo & 1 & 1 \\
\hline
\end{tabular}

As expectativas iniciais dos indivíduos relativamente ao processo de RVCC são diversificadas, sendo que as mais referidas são: a obtenção do diploma (3UR/2UE) " $E u$ esperava, sinceramente, em ficar com o diploma." (1.4.7.); o desconhecimento (2UR/1UE) "Era o desconhecido (..)" (1.4.3.).Dos indivíduos que referiram a expectativa relacionada com a obtenção do diploma, um prosseguiu estudos, encontrando-se, neste momento, a frequentar o 11. ${ }^{\circ}$ ano do Ensino Secundário (Recorrente, por Módulos Capitalizáveis).

Todos os outros elementos foram referidos apenas por um dos indivíduos.

\section{Quadro 12 - Dificuldades sentidas}




\begin{tabular}{|c|c|c|c|}
\hline C4-DIFICULDADES SENTIDAS & $\begin{array}{l}\text { Tecnologias de Informação e Comunicação } \\
\text { Gestão familiar } \\
\text { Matemática para a Vida } \\
\text { Pouco apoio dos amigos e colegas de trabalho } \\
\text { Falta de tempo }\end{array}$ & $\begin{array}{l}4 \\
4 \\
2 \\
2 \\
1\end{array}$ & $\begin{array}{l}2 \\
1 \\
2 \\
1 \\
1\end{array}$ \\
\hline C4 Total & & 13 & 3 \\
\hline
\end{tabular}

No que respeita às dificuldades mencionadas e identificadas no decorrer do processo, foram registadas 13 UR. Destas, seis dizem respeito às Áreas de Competência-Chave: Tecnologia de Informação e Comunicação (4UR/2UE) e Matemática para a Vida (2UR/2UE) "(...) ao nível da Matemática e dos computadores aquilo foi um bocado difícil." (1.4.10.); "Eu tinha medo dos computadores..." (1.5.6.). Pelos dados obtidos, consideramos que é relevante para um dos indivíduos a dificuldade que sentiu ao nível da gestão familiar do tempo necessário para conciliar as tarefas de casa/família com o processo -, e não propriamente à falta de apoio da família (cf. se confirma no quadro seguinte):

- "Em casa foi um bocadinho mais difícil por estarmos os dois." (3.5.10.);

- "Mais dificil era a minha falta de tempo." (3.5.7.).

\section{Quadro 13 - Facilidades}

\begin{tabular}{|l|l|c|c|}
\hline \multicolumn{1}{|c|}{ Sub-Categoria } & \multicolumn{1}{|c|}{ Conteúdo dos Indicadores } & $\begin{array}{c}\text { Unid. } \\
\text { Reg. }\end{array}$ & Unid. Enum. \\
\hline C5 - FACILIDADES & Apoio da família & 6 & 3 \\
& Local de realização do processo & 2 & 3 \\
& Conciliar horários (trabalho/processo/família) & 2 & 1 \\
& Espírito de cooperação do grupo & 1 & 1 \\
\hline C5 Total & União do grupo & $\mathbf{1 4}$ & 1 \\
\hline
\end{tabular}

Apesar da gestão familiar ter sido apontada por um dos indivíduos como uma das dificuldades (tempo necessário para as diferentes tarefas), todos evidenciaram, no entanto, o apoio da família (filhos, irmã,..) (6UR/3UE), na tomada de decisão em realizar o processo RVCC e no decorrer do mesmo, com todas as dificuldades adjacentes "Se estou na escola agradeço-o a ele!" [filho] (1.5.2.).; "As filhas, então incentivaram-me mesmo muito." (2.5.1.); "Fomos muito apoiados." (3.2.2.). Outro aspecto significativo para todos os indivíduos entrevistados foi o local de realização do processo (Escola Comunitária de São Miguel de Machede), o que é um sinal da importância destes processos funcionarem em regime de itinerância, indo ao encontro dos potenciais adultos interessados. Apenas um dos indivíduos referenciou que conciliar horários foi uma das facilidades (talvez porque trabalhava na própria Escola Comunitária e, por isso, dispunha de mais tempo) tendo realizado o processo no próprio local da entidade promotora do CRVCC "trabalhava na Suão e estava à vontade para conjugar os horários." (1.4.16.).

Face às dificuldades e constrangimentos sentidos, questionámos os indivíduos sobre as estratégias que utilizam para ultrapassar as dificuldades, conforme apresentado no Quadro 14. No que respeita ao processo, foi referida a formação complementar (4UR/2UE) como sendo uma resposta ao défice de competências evidenciadas por alguns indivíduos (interna ao processo; carácter residual, num total de 25 horas) "Fui à Epral uns dias para me explicarem como eram as coisas. "(1.5.5.) [TIC); "Mas com as "explicações" (...) consegui fazer."

A prática individual e a força de vontade também assumem relevância (4UR/2UE) nas estratégias utilizadas pelos indivíduos: "Era eu, na minha casa, que ia treinando sozinha." (1.5.8.); “(...) ia treinando" (3.4.8.); "Pois...com um bocadinho de força de vontade qualquer pessoa consegue." (1.5.21.).

\section{Quadro 14 - Estratégias para ultrapassar as dificuldades}




\begin{tabular}{|c|c|c|c|}
\hline Sub-Categoria & Conteúdo dos Indicadores & $\begin{array}{l}\text { Unid. } \\
\text { Reg. }\end{array}$ & Unid. Enum. \\
\hline 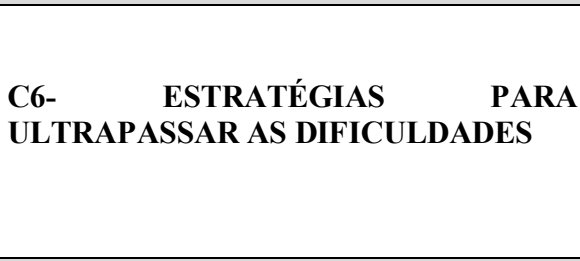 & $\begin{array}{l}\text { Formação complementar (interna ao processo RVCC) } \\
\text { Prática individual } \\
\text { Força de vontade } \\
\text { Ajuda dos outros (família, colega de trabalho,...) } \\
\text { Entreajuda entre o grupo } \\
\text { Mostrar aos outros "ser capaz de..." } \\
\text { Formação exterior (sessões MV) } \\
\end{array}$ & $\begin{array}{l}4 \\
4 \\
4 \\
4 \\
3 \\
1 \\
1\end{array}$ & $\begin{array}{l}2 \\
2 \\
2 \\
1 \\
1 \\
1 \\
1\end{array}$ \\
\hline C6 Total & & 21 & 3 \\
\hline
\end{tabular}

A ajuda obtida em contextos informais de aprendizagem, de onde se destacam a família, colegas de trabalho (4UR/IUE), é particularmente significativa para um dos indivíduos, o mesmo acontecendo com a entreajuda entre o grupo (3UR/1UE)

"Durante o processo nós íamo-nos ajudando uns aos outros." (3.3.4.); "Ela ia ajudava-me e fazíamos tudo em conjunto." [irmã] (3.4.9.)

Concluímos que a maioria das estratégias evidenciam um perfil de abordagem à aprendizagem de natureza intrínseca, isto é, ligado à motivação que cada um apresenta perante aquilo que tem de fazer ou aprender.

\section{8. $\quad$ Avaliação Geral do Processo de Reconhecimento, Validação e Certificação de Competências}

Quadro 15 - Avaliação geral da experiência nas diferentes dimensões

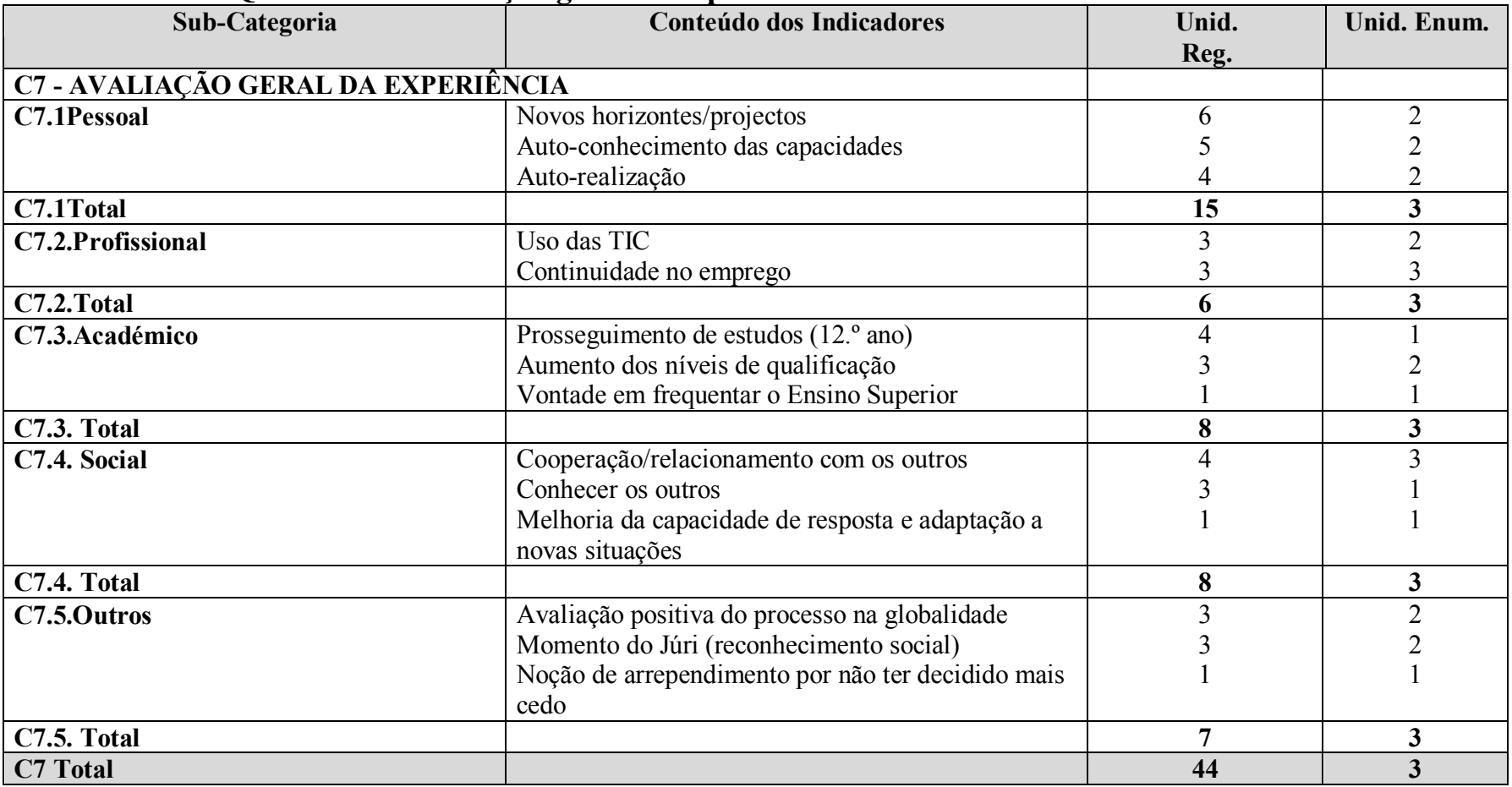

No que respeita à avaliação da experiência dos processos de RVCC, procurámos avaliar do impacto que este poderá ter tido na vida do adulto, nas diferentes dimensões: pessoal, profissional, académico, social e outros.

$\mathrm{Na}$ sua globalidade, foram registadas $44 \mathrm{UR}$, com maior incidência na dimensão pessoal (15UR).

No que respeita à dimensão pessoal dos indivíduos, foi realçado o contributo do processo ao nível da abertura e disponibilidade para novos projectos e desafios (6UR/2UE), no autoconhecimento das suas capacidades (5UR/2UE) e na auto-realização (4UR/2UE):

- "Fez-me abrir horizontes.." (1.7.1.);

- “(...) na parte de querer saber mais um pouco... sim...” (2.5.12); 
- (...) descobrirmos que sabemos e nem nos dávamos conta(..) (3.3.12.);

- “Com aquele dossier (...) consegui mais uma etapa da minha vida. (2.4.6.).

$\mathrm{Na}$ dimensão profissional, houve uma melhoria no uso das TIC, resultado da formação complementar e do impulso para a procura de formação individual nessa área na fase póscertificação, uma vez que "Sei ir à Internet, com o power point (...) também sei fazer alguma coisa." (1.6.9.). Se é evidente que aumentou o nível de qualificação dos indivíduos, o mesmo já não se poderá afirmar, relativamente aos níveis de empregabilidade. Um dos indivíduos manteve o local de trabalho (empregada doméstica), os outros alteraram a actividade profissional (serviços gerais e empregada doméstica) mas não para aquilo que desejariam, que seria (e será ainda) um emprego melhor em termos de salário e de situação profissional:

- "Não mudei de emprego." (2.5.11.);

- "Não me trouxe assim vantagens (...)" (1.7.10);

- "Em termos de trabalho (...) não tive não tive grandes frutos com isso mas posso vir a ter um dia." (3.6.10.).

$\mathrm{Na}$ dimensão académica, o que surge com maior relevância é o aumento dos níveis de qualificação, no caso do $2 .^{\circ}$ C.E.B. para a obtenção do diploma do $3 .^{\circ}$ C.E.B. $\left(9 .^{\circ}\right.$ ano de escolaridade) (3UR/2UE). O prosseguimento de estudos (12. ${ }^{\circ}$ ano) foi apenas relevante para um dos indivíduos. "Tenho uma maior escolaridade e isso é muito bom." (2.5.4.). "Alcancei o objectivo que tinha!"[9." ano] (3.6.5.) ou "Se não fosse o RVCC eu não poderia continuar a estudar". (1.7.12.).

Na dimensão social, há o destaque para a importância do processo ao nível da cooperação e relacionamento com os outros (4UR/3UE).

Outros aspectos referidos foram o momento do júri de validação, como um momento de reconhecimento social do processo.

De um modo geral, houve uma avaliação global positiva de todo o processo, evidenciando-se um maior impacto na dimensão pessoal da vida do adulto.

\subsection{Projectos de Aprendizagem Futuros}

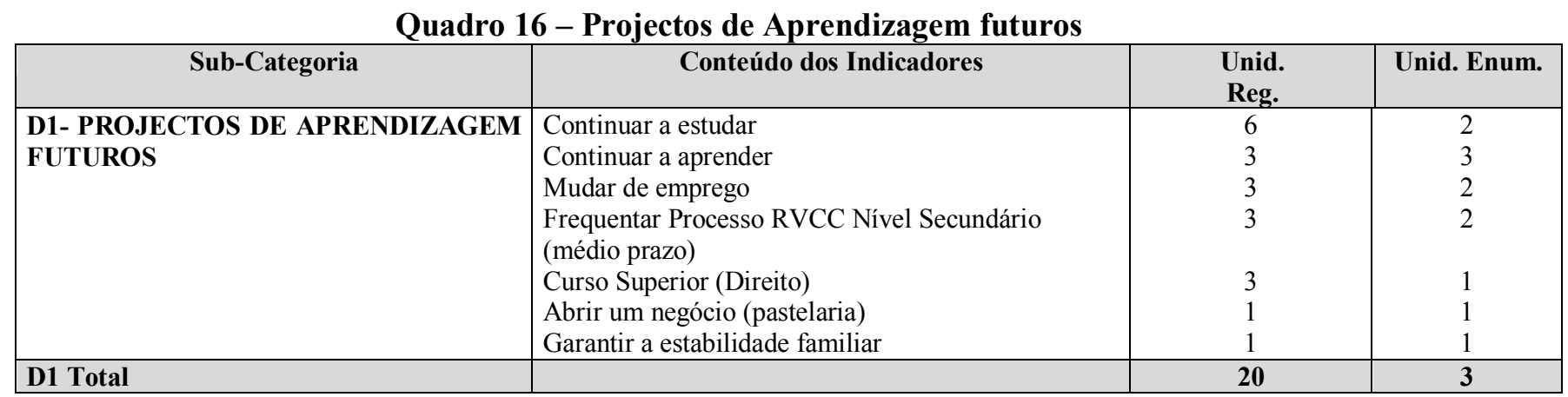

Quando questionados sobre os projectos de aprendizagem futuros, podemos agrupar as respostas obtidas em três campos: académico (15 UR), profissional (4 UR) e pessoal (1 UR).

Sendo uma das missões dos Centros Novas Oportunidades, orientar, aconselhar e motivar os indivíduos para percursos educativos e formativos ao longo da vida e ajustados às suas necessidades pessoais e profissionais e respectivas motivações, de referir que os indivíduos manifestaram a vontade em continuar a estudar (6UR/2 UE) e também em continuar a aprender (3UR/3UE). Ainda no campo académico, foi referida a intenção em dar continuidade ao percurso formativo através do Processo RVCC de Nível Secundário (3UR/2 UE) “Gostaria muito de ir e de conseguir.” (3.8.2.) ou "Só mesmo por realização pessoal..." (2.6.3.) [continuar pelo RVCC NS]. Para um dos indivíduos, assume importância a ideia de dar continuidade aos estudos de nível superior "Tenho ideia de ir para a Universidade, nem que seja só a experiência de um ano. ” (1.6.17.) 
No campo profissional, é relevante a vontade em mudar de emprego (3UR/2UE) ou, numa atitude mais empreendedora, um dos indivíduos menciona a vontade em abrir o seu próprio negócio "Gostava de mudar de emprego." (2.6.1.); (...) ter um emprego em que pudesse contactar com pessoas. Gostava de uma loja." (3.8.1.).

\section{Conclusões}

Como principais conclusões destacam-se:

(i) O papel importante da mulher no campo da família, ao nível da continuidade dos percursos educativos e formativos. Nos três casos estudados, verificamos que foi a mulher o elemento que assumiu o desafio de continuar o respectivo percurso formativo, motivando outros elementos da família (os maridos, em dois casos específicos de processo de RVCC);

(ii) A família como espaço privilegiado de aprendizagem informal. É no seio familiar que ocorrem muitas das aprendizagens referidas pelos sujeitos, como sejam as aprendizagens realizadas com a ajuda dos filhos, no uso do computador, entre outras.

(iii) A valorização do território local como espaço de aprendizagens significativas. Ao longo das três entrevistas foram identificados espaços da freguesia onde ocorreram aprendizagens, nomeadamente a Escola Comunitária, a Casa do Povo, a comunidade, no geral. A Escola Comunitária mereceu especial atenção nos discursos dos indivíduos, constituindo-se como um espaço onde ocorrem diversas actividades propícias à aprendizagem e ao exercício dos valores de cidadania (entreajuda, convívio, solidariedade,..). Foi aí que ocorreu, inclusive, a possibilidade de realizar os respectivos percursos de RVCC;

(iv) O reforço acentuado da dimensão pessoal nas respectivas vida das três adultas, após o percurso de rvcc. Para todos os sujeitos, as narrativas dos percursos de vida pessoal e profissional, realizadas no decorrer do processo de RVCC conduziu a alterações de índole pessoal, alterando a própria imagem de si própria. $\mathrm{O}$ autoconhecimento e a auto valorização pessoais, tornaram, certamente, mais felizes estes indivíduos, ajudando-os a saber quem são e essencialmente, o que poderão vir a ser no futuro, através de um processo de conscientização (Paulo Freire, 1977);

(v) (Re) construção dos projectos de vida e das motivações após os processos de rvcc. Independentemente, das dificuldades que possam existir, estes indivíduos, assumiram, nas entrevistas, uma perspectiva positiva, e até empreendedora, perante os projectos futuros;

(vi) o fraco impacto do processo de RVCC na dimensão profissional na vida dos adultos entrevistados, parece nos resultar do escasso tempo decorrido após a certificação (aproximadamente, dois anos para dois dos indivíduos.

\section{Referências Bibliográficas}

ALONSO, L. (2000). "A construção de um referencial de competência-chave para a cidadania e empregabilidade". Revista Saber Mais n. ${ }^{\circ}$ 5, 20-27.

ALONSO, L., et al (2001). Referencial de Competências-Chave - Educação e Formação de Adultos. Lisboa: ANEFA.

AMORIM, J. et al (2007). "Nem toda a comunidade cabe na educação e formação de adultos. in Albano Estrela et al (Orgs.) Actas do XV Colóquio da Secção Portuguesa da AFIRSE. Lisboa: Faculdade de Psicologia e de Ciências da Educação da Universidade de Lisboa (aguarda publicação). 
ARROTEIA, J. (2002). “Aspectos económicos e sociais da população nos Censos 2001”. in Seminário: Censos 2001. Lisboa: INE. (www.ine.pt/Censos 2001/Em Foco)

BARDIN, L. (1977). L'analyse de contenu. Paris: PUF.

BERNET, J. (1993). Otras Educaciones. Animación sociocultural, formación de adultos y ciudad educativa. Barcelona: Editorial Anthropos.

BOGDAN, R. \& BIKLEN, S., (1994). Investigação Qualitativa em Educação. Uma introdução à teoria e aos métodos. Porto: Porto Editora.

CANÁRIO, R. (1999). Educação de Adultos. Um Campo e uma Problemática. Lisboa: Educa.

CAVACO, C. (2002). Aprender fora da escola. Lisboa: Educa.

COMISSÃO EUROPEIA (2000). Memorando sobre Aprendizagem ao Longo da Vida. Bruxelas.

COMISSÃO EUROPEIA (2001). Tornar o Espaço Europeu de Aprendizagem ao Longo da Vida uma Realidade. Bruxelas.

COOMBS, P. (1968). The World Educational Crisis: A Systems Analysis. Oxford: Oxford University Press.

CORREIA , A. \& CABETE, D. (2002). “O valor do que aprendemos ao longo da nossa vida... e a importância do Sistema Português de Reconhecimento, Validação e Certificação de Competências". in Isabel Silva et al (Orgs.). Educação e Formação de Adultos: Factor de Desenvolvimento Inovação e Competitividade. Lisboa: ANEFA, 45-53.

COSTA, A. (2002). "Um processo de desenvolvimento social de competências e certificações.”. in Isabel Silva et al (Orgs.). Educação e Formação de Adultos Factor de Desenvolvimento Inovação e Competitividade. Lisboa: ANEFA, 7-11.

DGFV (2004). Reconhecimento e Validação de Competências. Instrumentos de mediação. Lisboa: Ministério da Educação.

FREIRE, P. (1977). Acção Cultural para a Libertação e Outros Escritos. Lisboa: Moraes Editores.

GOMES, M. (Coords.) (2006). Referencial de Competências-Chave para a Educação e Formação de Adultos - Nivel Secundário. Lisboa: DGFV.

IMAGINÁRIO, L. et al (2002). A Aprendizagem dos Adultos em Portugal: exame temático no âmbito da OCDE. Lisboa: ANEFA.

INSTITUTO DA EDUCAÇÃO DA UNESCO (1997). V Conferência Internacional sobre Educação de Adultos. Lisboa: Ministério da Educação. Secretaria de Estado da Educação e Inovação.

INE (2002). Censos 2001. Resultados Definitivos. Lisboa: INE.

JOSSO, M-C. (2002). Experiências de Vida e Formação. Lisboa: Educa.

LEITÃ̃, J. (2002). "Trabalho, Qualificação e novas Competências". in Isabel Silva et al (Orgs.). Educação e Formação de Adultos: Factor de Desenvolvimento Inovação e Competitividade. Lisboa: ANEFA, 73-76.

LESSARD, M. et al (1994). Investigação Qualitativa: Fundamentos e Práticas. Lisboa: Instituto Piaget.

MELO, A. \& BENAVEnTE, A. (1978). Educação Popular em Portugal 1974-1976. Lisboa: Livros Horizonte.

MOREIRA, A. \& PACHECO, J. (Orgs.). (2006). Globalização e Educação - Desafios para políticas e práticas . Lisboa: Porto Editora. 
NICO, B. (2006). "Avaliação de Competências: da arqueologia do bom à edificação do impossível" in Gérard Figari et al (Orgs.). Actas do XVII Colóquio da ADMEE-Europa. Lisboa: Faculdade de Psicologia e de Ciências de Educação da Universidade de Lisboa.

NOGUEIRA, A . (1996). Para uma Educação Permanente à Roda da Vida. Lisboa: Instituto de Inovação Educacional.

OSORIO, A. (2003). Educação Permanente e Educação de Adultos. Lisboa: Instituto Piaget.

PATRÍCIO, M. (2004). "Aprender na Escola do Alentejo". in J. Nico et al (Orgs.). Aprender no Alentejo - II Encontro Regional de Educação do Alentejo. Évora: Departamento de Pedagogia e Educação da Universidade de Évora. pp 13-16.

PEREIRA, J.(2005). Agentes, Factores, Suposições, Acasos e Outros Intervenientes na Modelação do Género. A construção social da diferenciação no discurso autobiográfico das mulheres pouco escolarizadas (Tese de Mestrado). Faculdade de Psicologia e de Ciências da Educação. Universidade de Coimbra. Coimbra.

PERRENOUD, P. (2000). "Construindo Competências". in Nova Escola. Entrevista de Paola Gentile e Roberta Bencini. Brasil. (www.dgidc.min-edu.pt)

SILVA, I., LEITÃO, J., TRIGO, M. (Orgs.). (2002). Educação e Formação de Adultos: Factor de Desenvolvimento Inovação e Competitividade. Lisboa: ANEFA.

TRIGO, M. (2002). "Tendências da Educação e da Formação das Pessoas". in Isabel Silva et al (Orgs.). Educação e Formação de Adultos: Factor de Desenvolvimento Inovação e Competitividade. Lisboa: ANEFA, pp. 23-30

VIEIRA, C. (2003). Educação e Desenvolvimento do Género. Os trilhos percorridos na Família (Tese de Doutoramento). Faculdade de Psicologia e de Ciências da Educação. Universidade de Coimbra. Coimbra.

VIEIRA, C. (2006). Educação Familiar. Estratégias para a Promoção da Igualdade de Género. Comissão para a Igualdade e para os Direitos das Mulheres. Colecção Mudar as Atitudes. Lisboa.

\section{Legislação referenciada:}

Decreto-Lei n. ${ }^{\circ} 74 / 91$, de 9 de Fevereiro Decreto-Lei n. ${ }^{\circ} 387 / 99$, de 28 de Setembro Portaria $.^{\circ} 1082-\mathrm{A} / 2001$, de 5 de Setembro Decreto-Lei n. ${ }^{\circ}$ 208/2002, de 17 de Outubro Decreto-Lei n. ${ }^{\circ}$ 213/2006, de 27 de Outubro Portaria n. ${ }^{\circ} 86 / 2007$, de 12 de Janeiro

\section{Sites consultados :}

www.novasoportunidades.gov.pt

www.dgfv.min-edu.pt www.dgidc.min-edu.pt www.ine.pt 
